\title{
The interaction between TERT promoter mutation and MGMT promoter methylation on overall survival of glioma patients: a meta-analysis
}

Huy Gia Vuong ${ }^{1,2}$, Thu Quynh Nguyen ${ }^{3}$, Tam N. M. Ngo ${ }^{3}$, Hoang Cong Nguyen ${ }^{3}$, Kar-Ming Fung ${ }^{1,2}$ and $\operatorname{lan}$ F. Dunn ${ }^{4^{*}}$

\begin{abstract}
Background: There are controversial results concerning the prognostic implication of TERT promoter mutation in glioma patients concerning MGMT status. In this meta-analysis, we investigated whether there are any interactions of these two genetic markers on the overall survival (OS) of glioma patients.

Methods: Electronic databases including PubMed and Web of Science were searched for relevant studies. Hazard ratio (HR) and its 95\% confidence interval (CI) for OS adjusted for selected covariates were calculated from the individual patient data (IPD), Kaplan-Meier curve (KMC), or directly obtained from the included studies.

Results: A total of nine studies comprising 2819 glioma patients were included for meta-analysis. Our results showed that TERT promoter mutation was associated with a superior outcome in MGMT-methylated gliomas (HR= $0.73 ; 95 \% \mathrm{Cl}=0.55-0.98 ; p$-value $=0.04)$, whereas this mutation was associated with poorer survival in gliomas without MGMT methylation ( $\mathrm{HR}=1.86 ; 95 \% \mathrm{Cl}=1.54-2.26$; $p$-value < 0.001$)$. TERT-mutated glioblastoma (GBM) patients with MGMT methylation benefited from temozolomide (TMZ) treatment ( $H R=0.33 ; 95 \% \mathrm{Cl}=0.23-0.47$; $p$ value <0.001). MGMT methylation was not related with any improvement in OS in TERT-wild type GBMs (HR $=0.80$; $95 \% \mathrm{Cl}=0.56-1.15 ; p$-value $=0.23)$.

Conclusions: The prognostic value of TERT promoter mutation may be modulated by MGMT methylation status. Not all MGMT-methylated GBM patients may benefit from TMZ; it is possible that only TERT-mutated GBM with MGMT methylation, in particular, may respond.
\end{abstract}

Keywords: Glioma, Glioblastoma, TERT, MGMT, Temozolomide, Overall survival, Meta-analysis

* Correspondence: lan-Dunn@ouhsc.edu

${ }^{4}$ Department of Neurosurgery, Oklahoma University Health Sciences Center, Oklahoma City, OK 73104, USA

Full list of author information is available at the end of the article

(c) The Author(s). 2020 Open Access This article is licensed under a Creative Commons Attribution 4.0 International License, which permits use, sharing, adaptation, distribution and reproduction in any medium or format, as long as you give appropriate credit to the original author(s) and the source, provide a link to the Creative Commons licence, and indicate if changes were made. The images or other third party material in this article are included in the article's Creative Commons licence, unless indicated otherwise in a credit line to the material. If material is not included in the article's Creative Commons licence and your intended use is not permitted by statutory regulation or exceeds the permitted use, you will need to obtain permission directly from the copyright holder. To view a copy of this licence, visit http://creativecommons.org/licenses/by/4.0/ The Creative Commons Public Domain Dedication waiver (http://creativecommons.org/publicdomain/zero/1.0/) applies to the data made available in this article, unless otherwise stated in a credit line to the data. 


\section{Background}

Gliomas are among the most common primary brain tumors in both adults and children [1]. Historically, glioma classifications and treatment options have been based on histological phenotypes, which lead to inconsistent outcomes. Recently, the 2016 revised classification of the World Health Organization (WHO) prioritized molecular signatures in pathologic determination. Brain tumors diagnosis, treatment, and prognosis were dependent on not only phenotypes but also genotypes [2-4]. This new classification emphasized the essential role of molecular testing in tailoring clinical decision and predicting patients' survival, in which $I D H 1$ and $1 \mathrm{p} / 19 \mathrm{q}$ status play an especially central role to classify the glioma tumors [1].

An emerging literature has provided an insight into the molecular characteristics of glioma which has enhanced the accuracy of diagnosis and prognosis. Telomerase reverse transcriptase (TERT) promoter mutation is one such marker. TERT plays an important role in telomerase activation leading to the immortality of malignant cells [5]. TERT C228T and C250T were the most common mutations [5]. Mutation of TERT promoter as a genetic event is frequently detected in $60-75 \%$ of glioblastomas (GBM), and associated with a poor prognosis $[5,6]$. While TERT promoter mutation showed a poor survival prognosis in glioma patients, $O^{6}$-methylguanine-DNA methyltransferase (MGMT) methylation has long been recognized as an important factor in treatment decisions [7], and is also a positive prognostic factor [8-12]. Our previous study, along with others, indicated that the prognostic value of TERT promoter mutation in gliomas is influenced by the status of $I D H$ mutations [5, 13-15].

The prognostic inter-relationship between TERT promoter mutations and MGMT methylation status has been unclear. The combination of TERT promoter mutations and MGMT promoter methylation has defined subgroups with noticeable responses to current treatments [10]. Some data have suggested that glioblastoma patients harboring MGMT methylation have a different prognosis depending on TERT promoter mutation status [16]; on the other hand, some studies have reported no association in the co-occurrence of TERT promoter mutation and MGMT methylation in glioma patients [14, 17-19].

In this study, we conducted a comprehensive metaanalysis to further understand whether TERT promoter mutation has any interaction with MGMT promoter methylation on overall survival (OS) of glioma patients.

\section{Methods}

\section{Literature search}

Our search was limited in two electronic databases including PubMed and Web of Science, from inception to October 2019. The below search terms were used: TERT AND MGMT. Potential studies were also searched by reviewing the citations within the included studies and reviews. We followed the recommendations of Preferred Reporting Items for Systematic Review and Meta-analysis (PRISMA) statement [20] (Supplementary Table 1).

\section{Selection criteria and abstract screening}

We brought all searched results from two electronic databases above into EndNote (Thomson Reuters, PA, US). Duplicated research papers were discarded. Titles and abstracts were independently assessed by two reviewers. We included research papers providing data regarding prognosis of MGMT promoter methylation and TERT promoter mutation on glioma patients' overall survival (OS). We excluded studies if they were studies on brain tumors other than glioma; studies lacking data on MGMT promoter methylation or TERT promoter mutation; case reports; reviews; posters, conference papers, theses or books; and duplicated articles. Any differences in opinions between reviewers were resolved by discussion and consensus.

\section{Full-text screening and data extraction}

Two reviewers independently reviewed all relevant research papers' full text. Potential data were extracted into a designated worksheet. The following data were extracted from full texts: authors, institution, city, country, year of publication, study design, number of patients, demographics (age and gender), WHO grade, follow-up periods, data of hazard ratio (HR) and its 95\% confidence intervals (CIs) on OS, and adjusted covariates if available. We directly obtained HR and its 95\% CI information from full text papers or calculated from the provided individual patient data (IPD). If not applicable, data were indirectly calculated from KMC using the methods by Tierney et al [21]. Any disagreements between two reviewers, if present, were solved again by discussion and consensus. Besides, we tried to contact the authors via email to request additional data or IPD if data were insufficiently provided in the original papers.

\section{Quality assessment and risk of bias analysis}

We evaluated the quality of included studies in our meta-analysis using the Newcastle - Ottawa Scale (NOS) [22]. Two reviewers independently scored the number of stars for cohort or case-control studies based on a developed checklist [22]. The maximum number of star (NOS) given is nine; studies awarded six stars or more were considered moderate to high-quality studies, and those with fewer than six stars were considered lowquality studies.

\section{Statistical analysis}

We used the multivariable Cox regression model with backward stepwise, analyzed by R (http://www.R-project.org), to assess the effects of TERT promoter mutations and MGMT 
promoter methylation on OS. Proportionality assumptions of the Cox regression models were assessed by log-log survival curves and with the use of Schoenfeld residuals. Hazard ratios are presented as mean and 95\% confidence intervals. HRs for OS were calculated from IPD, provided in original articles or via email request, and adjusted for confounding factors (age, gender, and WHO grade). When investigating the prognostic implication of MGMT promoter methylation in GBMs, data regarding chemotherapy (TMZ) was added into the adjusted covariates. Because of limited data, we did not include other molecular biomarkers such as $I D H$ mutation or $1 \mathrm{p} / 19 \mathrm{q}$ co-deletion as adjusted factors.

Pooled HRs for OS were calculated using the randommodel effect weighted by the inverse variance method. An $\mathrm{HR}>1$ indicated a worse prognosis in glioma patients with genetic alterations. If the authors provided several HR numbers in the same study, we selected the most powerful one for primary outcome analysis in ideal order: adjusted $\mathrm{HR}>$ unadjusted $\mathrm{HR}>\mathrm{HR}$ estimated from KMC. We used Review Manager 5.3 program (Cochrane Collaborative, Oxford, UK) for our analysis.

We assessed among-study heterogeneity using $I^{2}$ statistic which explored included studies' total variation is not by chance [23]. An $I^{2}$ statistic of $25-50 \%$ showed a low amount of heterogeneity, and $>50 \%$ indicated a high amount of heterogeneity [24]. The sources of heterogeneity were examined by using (i) subgroup analysis and (ii) sensitivity analysis.

\section{Risk of bias assessment}

Egger's regression test and funnel plot were done for evaluating the presence of publication. A $p$-value of less than 0.05 was considered statistically significant publication bias.

\section{Results}

We found 111 articles for abstract screening in which 38 studies were included for full text reading. After the full text screening step, we included eight papers satisfying our selection criteria. After contacting the corresponding authors of selected studies for potential unpublished data, we received a response from one paper providing their IPD [25]. Finally, a total of nine studies were included for meta-analyses comprising of 2819 glioma patients (Fig. 1) [16, 25-32]. The baseline characteristics of these studies were presented in Table 1.

The NOS tool was used to assess the quality of each included study. The number of stars awarded to each of

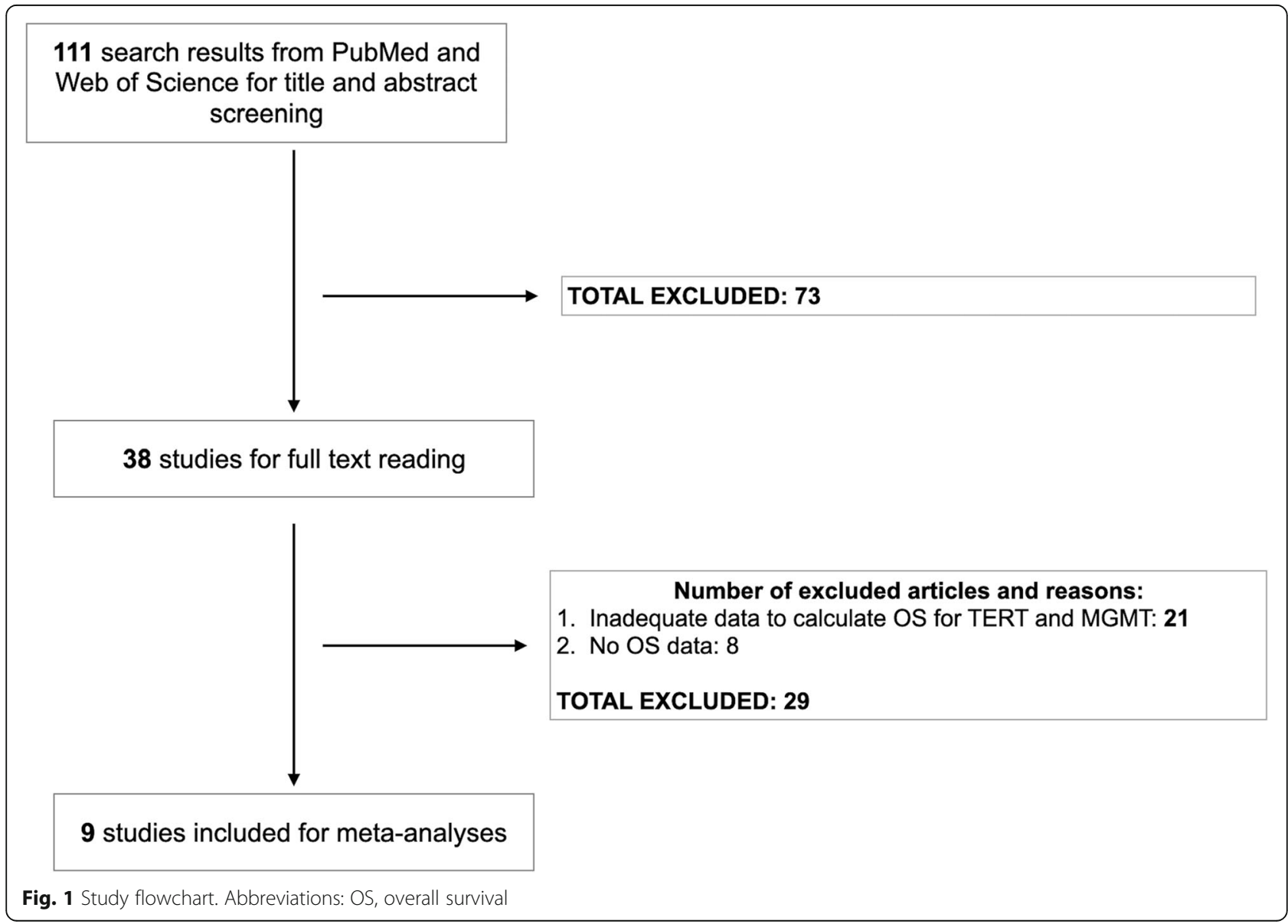


Table 1 Baseline characteristics of 9 included studies

\begin{tabular}{|c|c|c|c|c|c|c|c|c|}
\hline \multirow[t]{2}{*}{ Study } & \multirow[t]{2}{*}{ Institute } & \multirow[t]{2}{*}{ Country } & \multicolumn{3}{|c|}{ No. of cases } & \multicolumn{3}{|c|}{ NOS domain } \\
\hline & & & LGG & GBM & Total cases & Selection & Comparability & Outcome \\
\hline Arita 2016 [26] & Multicenter & Japan & 421 & 337 & 758 & 4 & 0 & 3 \\
\hline Ceccarelli 2016 [27] & The Cancer Genome Atlas & USA & 516 & 606 & 1122 & 4 & 0 & 3 \\
\hline Nguyen 2017 [16] & Multicenter & USA & 0 & 303 & 303 & 4 & 0 & 3 \\
\hline Park 2014 [25] & Seoul National University Hospital & Korea & 0 & 48 & 48 & 4 & 0 & 2 \\
\hline Picart 2018 [28] & Lyon University Hospital & France & 0 & 17 & 17 & 4 & 0 & 2 \\
\hline Picca 2018 [29] & OncoNeuro Tek & France & 30 & 86 & 116 & 4 & 0 & 2 \\
\hline Sasaki 2018 [30] & Multicenter & Japan & 26 & 114 & 140 & 4 & 0 & 3 \\
\hline Weller 2015 [31] & Multicenter & Germany & 137 & 0 & 137 & 4 & 0 & 3 \\
\hline Ye 2019 [32] & Xiangya Hospital & China & 0 & 178 & 178 & 4 & 0 & 2 \\
\hline
\end{tabular}

Abbreviations: LGG Lower-grade glioma, GBM Glioblastoma, NOS Newcastle Ottawa Scale

them ranged from six to seven stars. Details of given stars within each NOS domain were shown in Table 1.

The clinical implication of TERT promoter mutation on OS in association with MGMT methylation status in gliomas In MGMT-methylated (MGMT-meth) gliomas, the presence of the TERT promoter mutation was associated with an improved $\mathrm{OS}(\mathrm{HR}=0.73 ; 95 \% \mathrm{CI}=0.55-0.98$; $p$ - value $=0.04)$. There was a low heterogeneity among the included studies $\left(I^{2}=37 \%\right)$ (Fig. $\left.2 \mathrm{a}\right)$. After omitting the Sasaki et al. study [30], there was no change in the overall result and the among-study heterogeneity was insignificant $\left(\mathrm{HR}=0.68 ; 95 \% \mathrm{CI}=0.54-0.85 ; I^{2}=6 \%\right)$.

On the other hand, TERT promoter mutation was an indicator of worse outcome in MGMT-unmethylated (MGMT-unmeth) gliomas $(\mathrm{HR}=1.86 ; 95 \% \mathrm{CI}=1.54-$

\begin{tabular}{|c|c|c|c|c|c|c|c|}
\hline $\begin{array}{l}\text { A } \\
\text { Study or Subgroup }\end{array}$ & log[Hazard Ratio] & SE & Weight & $\begin{array}{c}\text { Hazard Ratio } \\
\text { IV, Random, } 95 \% \mathrm{Cl}\end{array}$ & \multicolumn{3}{|c|}{$\begin{array}{c}\text { Hazard Ratio } \\
\text { IV, Random, 95\% CI }\end{array}$} \\
\hline Arita 2016 & -0.6931 & 0.212 & $21.5 \%$ & $0.50[0.33,0.76]$ & \multicolumn{2}{|c|}{$\rightarrow-$} & \\
\hline Ceccarelli 2016 & -0.1393 & 0.314 & $14.2 \%$ & $0.87[0.47,1.61]$ & \multirow{2}{*}{$\longrightarrow$} & & \\
\hline Nguyen 2016 & -0.462 & 0.265 & $17.3 \%$ & $0.63[0.37,1.06]$ & & & \\
\hline Park 2014 & -0.607 & 0.671 & $4.4 \%$ & $0.54[0.15,2.03]$ & 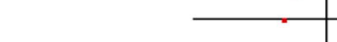 & & \\
\hline Picca 2018 & 1.0403 & 1.435 & $1.1 \%$ & $2.83[0.17,47.13]$ & & & \\
\hline Sasaki 2018 & 0.6259 & 0.453 & $8.5 \%$ & $1.87[0.77,4.54]$ & & & \\
\hline Weller 2015 & -0.734 & 0.425 & $9.4 \%$ & $0.48[0.21,1.10]$ & & & \\
\hline Ye 2019 & -0.1278 & 0.19 & $23.5 \%$ & $0.88[0.61,1.28]$ & $\rightarrow$ & t & \\
\hline \multicolumn{3}{|l|}{ Total $(95 \% \mathrm{Cl})$} & $100.0 \%$ & $0.73[0.55,0.98]$ & & & \\
\hline \multicolumn{5}{|c|}{$\begin{array}{l}\text { Heterogeneity: } \mathrm{Tau}^{2}=0.06 ; \mathrm{Chi}^{2}=11.12, \mathrm{df}=7(\mathrm{P}=0.13) ; \mathrm{I}^{2}=37 \% \\
\text { Test for overall effect: } \mathrm{Z}=2.07(\mathrm{P}=0.04)\end{array}$} & $\begin{array}{lll}0.01 & 0.1 & 1 \\
\text { Favours [experimental] }\end{array}$ & $\begin{array}{c}10 \\
\text { Favours [control] }\end{array}$ & \multirow[t]{2}{*}{100} \\
\hline $\begin{array}{l}\text { B } \\
\text { Study or Subgroup }\end{array}$ & log[Hazard Ratio] & SE & Weight & $\begin{array}{c}\text { Hazard Ratio } \\
\text { IV, Random, } 95 \% \mathrm{Cl} \\
\end{array}$ & \multicolumn{2}{|c|}{$\begin{array}{c}\text { Hazard Ratio } \\
\text { IV, Random, } 95 \% \mathrm{Cl} \\
\end{array}$} & \\
\hline Arita 2016 & 0.5653 & 0.143 & $48.0 \%$ & $1.76[1.33,2.33]$ & & -1 & \\
\hline Ceccarelli 2016 & 0.9821 & 0.655 & $2.3 \%$ & $2.67[0.74,9.64]$ & & & \\
\hline Nguyen 2016 & 0.5188 & 0.201 & $24.3 \%$ & $1.68[1.13,2.49]$ & & $\longrightarrow$ & \\
\hline Park 2014 & 0.2731 & 0.84 & $1.4 \%$ & $1.31[0.25,6.82]$ & & & \\
\hline Picart 2017 & 0.4121 & 0.718 & $1.9 \%$ & $1.51[0.37,6.17]$ & & & \\
\hline Sasaki 2018 & 0.8671 & 0.336 & $8.7 \%$ & $2.38[1.23,4.60]$ & & $\longrightarrow$ & \\
\hline Weller 2015 & 0.3185 & 0.63 & $2.5 \%$ & $1.38[0.40,4.73]$ & & & \\
\hline Ye 2019 & 0.9821 & 0.298 & $11.0 \%$ & $2.67[1.49,4.79]$ & & $\longrightarrow$ & \\
\hline Total $(95 \% \mathrm{Cl})$ & & & $100.0 \%$ & $1.86[1.54,2.26]$ & & $>$ & \\
\hline $\begin{array}{l}\text { Heterogeneity: } \mathrm{Tau}^{2}= \\
\text { Test for overall effect }\end{array}$ & $\begin{array}{l}0.00 ; \mathrm{Chi}^{2}=3.21, \mathrm{~d} \\
Z=6.29(\mathrm{P}<0.000\end{array}$ & $\begin{array}{l}\mathrm{df}=7(\mathrm{P} \\
001)\end{array}$ & $P=0.87)$ & $1^{2}=0 \%$ & $\begin{array}{ll}0.01 & 0.1 \\
\text { Favours [experimental] }\end{array}$ & $\begin{array}{c}10 \\
\text { Favours [control] }\end{array}$ & 100 \\
\hline
\end{tabular}


2.26; $p$-value < 0.001) (Fig. 2b). No heterogeneity was detected among the analyzed data $\left(I^{2}=0 \%\right)$.

\section{The prognostic impact MGMT promoter methylation} stratified by TERT promoter mutation status in gliomas Calculated data were adjusted for age, gender, and WHO grade, if applicable. MGMT promoter methylation was associated with a superior OS in both TERT-mut $(\mathrm{HR}=0.29$; 95\% CI $\left.=0.21-0.39 ; I^{2}=44 \%\right)$ and TERT-wt gliomas $(\mathrm{HR}=$ $\left.0.54 ; 95 \% \mathrm{CI}=0.39-0.74 ; I^{2}=19 \%\right)$. Sensitivity analysis showed a robust result and the among-study heterogeneity was completely removed.

\section{Subgroup analyses regarding the impact of TERT promoter mutation and MGMT methylayion on overall survival of LGGs and GBMs}

Table 2 shows that among MGMT-met LGGs and GBMs, TERT promoter mutation did not have a significant impact on OS ( $p$-value $=0.18$ and 0.11 , respectively). On the other side, this mutation resulted in a compromised OS among MGMT-unmet LGGs and GBMs.

In TERT-mut and TERT-wt LGGs and GBMs subgroups, MGMT methylation was associated with a favorable OS in most of the subgroups. Heterogeneity was present among a few LGG subgroups.

\section{TMZ treatment in MGMT-methylated GBM patients}

Three studies with sufficient data regarding chemotherapy treatment were included for meta-analysis [16, 26, 30]. While focusing on GBMs and adjusted for age, gender, and TMZ treatment, only TERT-mut GBM patients with MGMT methylation appeared to benefit from TMZ treatment $\left(\mathrm{HR}=0.33 ; 95 \% \mathrm{CI}=0.23-0.47 ; I^{2}=44 \%\right)$, whereas MGMT methylation did not appear to be associated with improvement in OS in TERT-wt GBMs (HR =0.80; 95\% $\mathrm{CI}=0.56-1.15 ; I^{2}=0 \%$ ) (Fig. 3). After omitting data from the Sasaki et al. study [30], the among-study heterogeneity in the former analysis completely disappeared and the overall result was unchanged $(\mathrm{HR}=0.30 ; 95 \% \mathrm{CI}=0.23-$ $\left.0.39 ; I^{2}=0 \%\right)$.

\section{Publication bias}

Because of the small number of included studies (less than 10), we did not perform the Egger's regression test and funnel plot observation due to a high risk of bias.

\section{Discussion}

There have been robust efforts to decipher the molecular biomarkers of glioma and their prognostic significance as well as apply these findings to clinical practice, particularly in choosing appropriate candidates for initial chemotherapy [13, 30, 33-37]. TERT promoter mutation and MGMT methylation status are among the most important markers. MGMT promoter methylation is one of the few treatment-relevant markers, encoding an enzyme that removes mutagenic methylating lesions from the $\mathrm{O}^{6}$ guanine position. Methylation of the MGMT promoter leads to low expression of MGMT and inactivation of the repair protein, rendering tumor cells more sensitive to effects of alkylating agents [38]. Consequently, MGMT methylation is considered a favorable prognosis marker associated with longer survival outcomes [39].

Additionally, mutation in the TERT promoter has shown to have prognostic value across a range of tumors $[4,13,33,40-44]$. Mutations in this promoter region maintain telomere length and tumor cell survival which plays a crucial role in cancer development [45]. Interestingly, high TERT activity occurs in $90 \%$ of human cancers [46], including gliomas (70\%) [47].

Our study demonstrated that TERT promoter mutations showed contradicting effects in MGMT-meth and MGMT-unmeth gliomas. In MGMT-meth gliomas, TERT promoter mutation was correlated with a favorable survival outcome. In contrast, in MGMT-unmeth gliomas, TERT promoter mutation was regarded as an indicator of poor prognosis. From our results, the OS of

Table 2 Subgroup analyses concerning the impact of TERT promoter mutation and MGMT methylation on overall survival of LGGs and GBMs

\begin{tabular}{|c|c|c|c|c|c|c|}
\hline \multicolumn{3}{|c|}{ Subgroups } & \multirow{2}{*}{$\frac{\text { HR }}{0.62}$} & \multirow{2}{*}{$\frac{95 \% \mathrm{Cl}}{0.31-1.24}$} & \multirow{2}{*}{$\begin{array}{l}p \text {-value } \\
0.180\end{array}$} & \multirow{2}{*}{$\frac{r^{2}(\%)}{60}$} \\
\hline$\overline{\mathrm{LGG}}$ & TERT-mut vs TERT-wt & MGMT-met & & & & \\
\hline & & MGMT-unmet & 1.47 & $1.01-2.16$ & 0.045 & 0 \\
\hline \multirow[t]{2}{*}{ GBM } & & MGMT-met & 0.79 & $0.59-1.05$ & 0.110 & 17 \\
\hline & & MGMT-unmet & 1.93 & $1.55-2.41$ & $<0.001$ & 0 \\
\hline \multirow[t]{2}{*}{ LGG } & MGMT-met vs MGMT-unmet & TERT-mut & 0.26 & $0.11-0.63$ & 0.003 & 65 \\
\hline & & TERT-wt & 0.41 & $0.26-0.64$ & $<0.001$ & 0 \\
\hline \multirow[t]{2}{*}{ GBM } & & TERT-mut & 0.31 & $0.25-0.39$ & $<0.001$ & 0 \\
\hline & & TERT-wt & 0.85 & $0.67-1.07$ & 0.160 & 0 \\
\hline
\end{tabular}

Abbreviations: Cl Confidence interval, met Methylated, GBM Glioblastoma, HR Hazard ratio, LGG Lower-grade glioma, mut Mutated, unmet Unmethylated, 


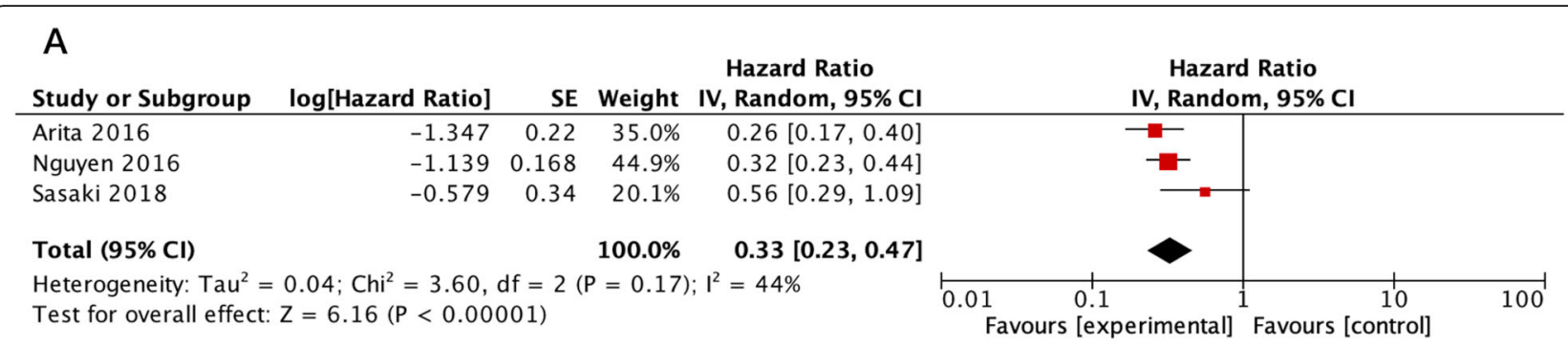

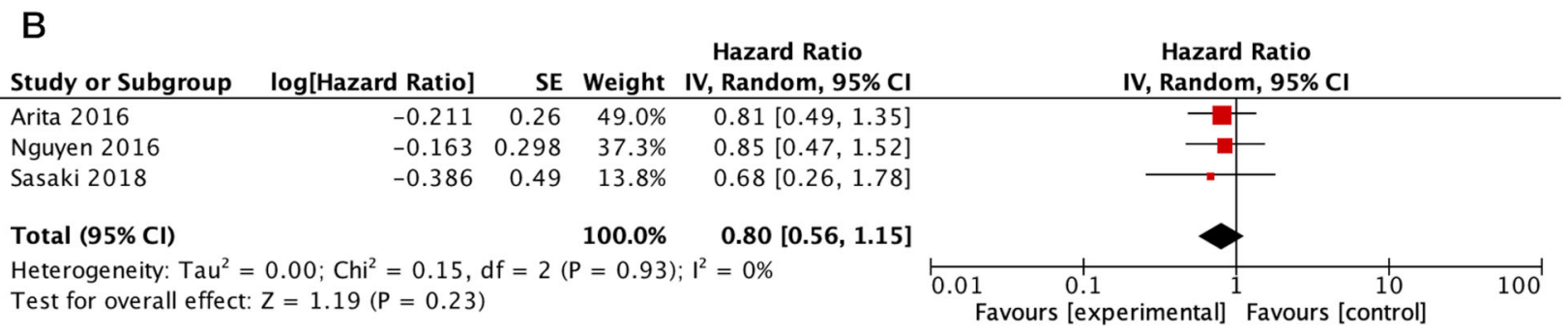

Fig. 3 Forest plots illustrating the clinical significance of MGMT promoter methylation in TERT-mut (a) and TERT-wt GBMs (b) treated by TMZ. Abbreviations: IV, inverse variance; $\mathrm{Cl}$, confidence interval; SE, standard error

gliomas can be further stratified into four distinct survival subgroups with ascending survival time as follow: TERT-mut/MGMT-unmeth $\quad<\quad T E R T$-wt/MGMTunmeth $<$ TERT-wt/MGMT-meth $<$ TERT-mut/ MGMT-meth which is consistent with previous reports $[16,26]$. This risk stratification will help clinicians better predict patient survival and tailor treatment decisions accordingly. However, the underlying mechanism on how MGMT promoter methylation modulates TERT promoter mutation has not been well elucidated. In one recent study, the TERT-mut/MGMT-unmeth GBM was associated with worse magnetic resonant imaging (MRI) characteristics such as low apparent diffusion coefficient values, obvious edema, obvious necrosis, unobvious noncontrast enhancing tumor, deep white matter invasion, and a high Ki-67 labeling rather than other groups [10]. On the other hand, it is interesting to note that TERT promoter mutation is an independent prognostic marker in other cancers (e.g., melanoma, thyroid cancer, urothelial carcinoma) and is not influenced by other mutations such as RAS or BRAF mutations [43, 44, 48-50]. In gliomas, the prognostic impact of TERT promoter mutation has been known to be modulated by $I D H$ mutations [13]. Therefore, the principal concept of these modulations in glioma warrants further mechanistic investigation. In contrast to TERT promoter mutation, the prognostic impact of MGMT methylation was not dependent on other confounding factors including the status of TERT promoter mutation, emphasizing the important role of MGMT methylation as an independent prognostic marker in gliomas.

While the positive prognosis role of MGMT methylation in patients treated with TMZ has been observed in many studies [9, 36, 51-54], there were still conflicting results regarding the prognostic value of this genetic marker in GBM patients [34, 55]. It raises the question that there might be other factors affecting the responsiveness to TMZ besides MGMT methylation status. Our results led us to the observation that TERT promoter mutation was associated with the MGMT methylation benefit in GBM patients treated by TMZ whereas, in the TERT-wt group, MGMT methylation was not associated with improved OS in these patients. As a result, it is crucial to test for TERT promoter mutation and MGMT methylation in GBM patients who are eligible for TMZ chemotherapy.

The biological mechanism of interaction between TERT promoter mutation and MGMT methylation that may influence sensitivity to TMZ treatment of gliomas has not yet clearly defined. We believe that the efficacy of TMZ depends on both telomerase hyperactivity and muted MGMT gene expression. Based on our results, we assumed that MGMT promoter methylation might increase sensitivity to TMZ, mainly in the context of TERT promoter mutation. MGMT encodes an enzyme that removes alkylating lesions added by TMZ from the O6 guanine position. Methylation of MGMT promoter leads to low expression of MGMT and silence of repair protein, which makes tumor cells more sensitive to effects of TMZ [56]. Consequently, MGMT methylated status is considered a favorable prognostic marker associated with longer survival outcomes [8, 9, 57, 58]. Our immune system's response to tumor may be in play as well. TMZ may improve tumor antigen presentation to $\mathrm{T}$ lymphocytes in a process known as cross-priming [59]. The facilitation of cell division by the TERT 
promoter mutation may lead cancerous cells to divide more quickly, divide, the more cell death and tumor lysis occur, which might increase releasing of tumor antigen. As a result, patients harboring TERT promoter mutation and MGMT methylation might show survival benefit with TMZ. Further investigation is required to understand clearly how these two genetic markers influence treatment response. In the unmethylated MGMT subgroup, TMZ's cytotoxic alkylating effect is counteracted by the DNA repair enzyme. Other studies have also shown no significant survival benefit of TMZ chemotherapy in MGMT unmethylated patients $[8,9,60]$.

Acknowledging minimal heterogeneity, we believe that our meta-analysis provides robust and useful directionality regarding the potential interaction between TERT and MGMT in glioma patients. However, we acknowledge that our meta-analysis is mainly based on retrospective studies which can lead to unavoidable selection biases. Moreover, our results were calculated from both individual and aggregate level data. While we attempted to minimize the differences in demographic and therapeutic data among the included studies by adjusting for various covariates, it should be noted that there might still be some discrepancies among different datasets such as molecular profiling of other genetic markers, tumor locations, and salvage therapies throughout the treatment of patients. It is of interest to perform subgroup analyses regarding effects of TERT promoter subtypes (C228T versus C250T) on patient OS. However, these data were only provided in two studies which is insufficient for further analysis.

\section{Conclusions}

In summary, TERT promoter mutation should not be used as a single predictive factor in gliomas. Instead, it should be interpreted in combination with MGMT methylation status. In addition, TERT promoter mutation seems to be a useful biomarker in clinically evaluating sensitivity to TMZ for treatment of glioma patients who carry MGMT methylated status.

\section{Supplementary information}

Supplementary information accompanies this paper at https://doi.org/10. 1186/s12885-020-07364-5.

Additional file 1. Table 1. The PRISMA checklist

\footnotetext{
Abbreviations

Cl: Confidence interval; GBM: Glioblastoma; HR: Hazard ratio; IPD: Individual patient data; KMC: Kaplan Meier curve; OS: Overall survival; LGG: Lower-grade glioma; MGMT: $0^{6}$-methylguanine-DNA methyltransferase; MGMTmeth: MGMT-methylated; MGMT-unmeth: MGMT-unmethylated; NOS: Newcastle-Ottawa Scale; TERT: Telomerase reverse transcriptase; TERTmut: TERT-mutated; TERT-wt: TERT-wild-type; TMZ: Temozolomide; WHO: World Health Organization
}

Acknowledgements

Not applicable.

\section{Disclosure}

The authors have nothing to disclose

\section{Authors' contributions}

HGV: conceptualization, data curation, formal analysis, investigation, methodology, project administration, software, validation, supervision, writing-review, and editing. TQN: data curation, formal analysis, investigation, software, supervision, writing-review, and editing. HCN: data curation, formal analysis, investigation, validation, supervision, writing-review, and editing.

TNMN: data curation, formal analysis, investigation, software, methodology, validation, supervision, writing-review, and editing. KMF: data curation, formal analysis, investigation, methodology, software, validation, supervision, writing-review, and editing. IFD: conceptualization, data curation, formal analysis, investigation, methodology, project administration, software, validation, supervision, writing-review, editing, and supervision. The authors have read and approved the manuscript.

\section{Funding}

This study receives no funding support.

Availability of data and materials

Not applicable.

Ethics approval and consent to participate

Not applicable.

\section{Consent for publication}

Not applicable.

\section{Competing interests}

The authors declare no conflicts of interest.

\section{Author details}

'Department of Pathology, Oklahoma University Health Sciences Center, Oklahoma City, OK 73104, USA. ${ }^{2}$ Stephenson Cancer Center, Oklahoma University Health Sciences Center, Oklahoma City, OK 73104, USA. ${ }^{3}$ Faculty of Medicine, Pham Ngoc Thach University of Medicine, Ho Chi Minh City 700-000, Vietnam. ${ }^{4}$ Department of Neurosurgery, Oklahoma University Health Sciences Center, Oklahoma City, OK 73104, USA.

Received: 12 July 2020 Accepted: 31 August 2020

Published online: 21 September 2020

\section{References}

1. Louis DN, Perry A, Reifenberger G, Von Deimling A, Figarella-Branger D, Cavenee WK, et al. The 2016 World Health Organization classification of tumors of the central nervous system: a summary. Acta Neuropathol. 2016; 131(6):803-20.

2. Kramar F, Minarik M, Belsanova B, Halkova T, Bradac O, Netuka D, et al. Genetic and epigenetic factors affecting development and prognosis of brain Gliomas - a review of cur rent knowledge. Ceska a Slovenska Neurologie a Neurochirurgie. 2016;79(4):400-5.

3. Hainfellner JA. Translating brain tumor biomarkers into diagnostic use. J Neurol Sci. 2015;357:E500.

4. Gao K, Li G, Qu Y, Wang M, Cui B, Ji M, et al. TERT promoter mutations and long telomere length predict poor survival and radiotherapy resistance in gliomas. Oncotarget. 2016;7(8):8712-25.

5. Killela PJ, Reitman ZJ, Jiao Y, Bettegowda C, Agrawal N, Diaz LA, et al. TERT promoter mutations occur frequently in gliomas and a subset of tumors derived from cells with low rates of self-renewal. Proc Natl Acad Sci. 2013; 110(15):6021-6.

6. Nonoguchi N, Ohta T, Oh J-E, Kim Y-H, Kleihues P, Ohgaki H. TERT promoter mutations in primary and secondary glioblastomas. Acta Neuropathol. 2013; 126(6):931-7.

7. Heuling ES, Knab F, Radke J, Eskilsson E, Martinez-Ledesma E, Koch A, et al. Prognostic relevance of tumor purity and interaction with MGMT methylation in Glioblastoma. Mol Cancer Res. 2017;15(5):532-40. 
8. Everhard S, Kaloshi G, Criniere E, Benouaich-Amiel A, Lejeune J, Marie Y, et al. MGMT methylation: a marker of response to temozolomide in lowgrade gliomas. Ann Neurol. 2006;60(6):740-3.

9. Hegi ME, Diserens AC, Gorlia T, Hamou MF, de Tribolet N, Weller M, et al. MGMT gene silencing and benefit from temozolomide in glioblastoma. N Engl J Med. 2005;352(10):997-1003.

10. Shu C, Wang Q, Yan X, Wang J. The TERT promoter mutation status and MGMT promoter methylation status, combined with dichotomized MRIderived and clinical features, predict adult primary glioblastoma survival. Cancer Med. 2018;7(8):3704-12

11. Dubbink HJ, Atmodimedjo PN, Kros JM, French PJ, Sanson M, Idbaih A, et al. Molecular classification of anaplastic oligodendroglioma using next-generation sequencing: a report of the prospective randomized EORTC brain tumor group 26951 phase III trial. Neuro-oncology. 2016;18(3):388-400

12. Nakagawa Y, Sasaki H, Ohara K, Ezaki T, Toda M, Ohira T, et al. Clinical and molecular prognostic factors for long-term survival of patients with Glioblastomas in single-institutional consecutive cohort. World Neurosurg. 2017; 106:165-73.

13. Vuong HG, Altibi AMA, Duong UNP, Ngo HTT, Pham TQ, Chan AK, et al. TERT promoter mutation and its interaction with IDH mutations in glioma: combined TERT promoter and IDH mutations stratifies lower-grade glioma into distinct survival subgroups-a meta-analysis of aggregate data. Crit Rev Oncol Hematol. 2017:120:1-9.

14. Labussiere M, Boisselier B, Mokhtari K, Di Stefano AL, Rahimian A, Rossetto $M$, et al. Combined analysis of TERT, EGFR, and IDH status defines distinct prognostic glioblastoma classes. Neurology. 2014;83(13):1200-6.

15. Eckel-Passow JE, Lachance DH, Molinaro AM, Walsh KM, Decker PA, Sicotte $\mathrm{H}$, et al. Glioma groups based on 1p/19q, IDH, and TERT promoter mutations in tumors. N Engl J Med. 2015;372(26):2499-508.

16. Nguyen HN, Lie A, Li T, Chowdhury R, Liu F, Ozer B, et al. Human TERT promoter mutation enables survival advantage from MGMT promoter methylation in IDH1 wild-type primary glioblastoma treated by standard chemoradiotherapy. Neuro-oncology. 2017;19(3):394-404.

17. Arita H, Yamasaki K, Kanemura Y, Mukasa A, Nagane M, Ueki K, et al. A combination of TERT and mgmt improves the prognostication of glioblastomas. Neuro-oncology. 2017;19:14.

18. Nencha U, Rahimian A, Giry M, Sechi A, Mokhtari K, Polivka M, et al. TERT promoter mutations and rs2853669 polymorphism: prognostic impact and interactions with common alterations in glioblastomas. J Neurooncol. 2016; 126(3):441-6.

19. Spiegl-Kreinecker S, Lotsch D, Ghanim B, Pirker C, Mohr T, Laaber M, et al. Prognostic quality of activating TERT promoter mutations in glioblastoma: interaction with the rs2853669 polymorphism and patient age at diagnosis. Neuro-oncology. 2015;17(9):1231-40.

20. Moher D, Liberati A, Tetzlaff J, Altman DG. Preferred reporting items for systematic reviews and meta-analyses: the PRISMA statement. PLoS Med. 2009;6(7):e1000097.

21. Tierney JF, Stewart LA, Ghersi D, Burdett S, Sydes MR. Practical methods for incorporating summary time-to-event data into meta-analysis. Trials. 2007;8:16.

22. Wells G, Shea B, O'connell D, Peterson J, Welch V, Losos M, et al. The Newcastle-Ottawa scale (NOS) for assessing the quality of nonrandomised studies in meta-analyses; 2000.

23. Higgins J, Thompson SG. Quantifying heterogeneity in a meta-analysis. Stat Med. 2002;21(11):1539-58.

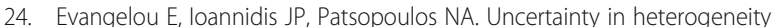
estimates in meta-analyses. BMJ: Brit Med J. 2007;335(7626):914-6.

25. Park CK, Lee SH, Kim JY, Kim JE, Kim TM, Lee ST, et al. Expression level of hTERT is regulated by somatic mutation and common single nucleotide polymorphism at promoter region in glioblastoma. Oncotarget. 2014;5(10):3399-407.

26. Arita H, Yamasaki K, Matsushita Y, Nakamura T, Shimokawa A, Takami H, et al. A combination of TERT promoter mutation and MGMT methylation status predicts clinically relevant subgroups of newly diagnosed glioblastomas. Acta Neuropathol Commun. 2016;4(1):79.

27. Ceccarelli M, Barthel FP, Malta TM, Sabedot TS, Salama SR, Murray BA, et al. Molecular profiling reveals biologically discrete subsets and pathways of progression in diffuse Glioma. Cell. 2016;164(3):550-63.

28. Picart T, Barritault M, Berthillier J, Meyronet D, Vasiljevic A, Frappaz D, et al. Characteristics of cerebellar glioblastomas in adults. J Neurooncol. 2018;136(3):555-63.

29. Picca A, Berzero G, Bielle F, Touat M, Savatovsky J, Polivka M, et al. FGFR1 actionable mutations, molecular specificities, and outcome of adult midline gliomas. Neurology. 2018;90(23):e2086-94.
30. Sasaki T, Fukai J, Kodama Y, Hirose T, Okita Y, Moriuchi S, et al. Characteristics and outcomes of elderly patients with diffuse gliomas: a multi-institutional cohort study by Kansai molecular diagnosis network for CNS tumors. J Neurooncol. 2018;140(2):329-39.

31. Weller M, Weber RG, Willscher E, Riehmer V, Hentschel B, Kreuz M, et al. Molecular classification of diffuse cerebral WHO grade I//II gliomas using genome- and transcriptome-wide profiling improves stratification of prognostically distinct patient groups. Acta Neuropathol. 2015;129(5):679-93.

32. Ye N, Jiang N, Feng C, Wang F, Zhang H, Bai HX, et al. Combined therapy sensitivity index based on a 13-gene signature predicts prognosis for IDH wild-type and MGMT promoter Unmethylated Glioblastoma patients. J Cancer. 2019;10(22):5536-48.

33. Arita H, Yamasaki K, Nakamura T, Shirahata M, Kobayashi K, Tamura K, et al. TERT promoter mutation is a poor prognostic marker for GBMS and interacts with mgmt methylation status. Neuro-oncology. 2016;18:108.

34. Arvold ND, Cefalu M, Wang Y, Zigler C, Schrag D, Dominici F. Comparative effectiveness of radiotherapy with vs. without temozolomide in older patients with glioblastoma. J Neurooncol. 2017;131(2):301-11.

35. Chen R, Smith-Cohn M, Cohen AL, Colman H. Glioma subclassifications and their clinical significance. Neurotherapeutics. 2017;14(2):284-97.

36. Franceschi E, Depenni R, Paccapelo A, Ermani M, Faedi M, Sturiale C, et al. Which elderly newly diagnosed glioblastoma patients can benefit from radiotherapy and temozolomide? A PERNO prospective study. J Neurooncol. 2016;128(1):157-62.

37. Vuong HG, Altibi AMA, Duong UNP, Ngo HTT, Pham TQ, Fung KM, et al. BRAF mutation is associated with an improved survival in Glioma-a systematic review and meta-analysis. Mol Neurobiol. 2018;55(5):3718-24.

38. Mansouri A, Hachem LD, Mansouri S, Nassiri F, Laperriere NJ, Xia D, et al. MGMT promoter methylation status testing to guide therapy for glioblastoma: refining the approach based on emerging evidence and current challenges. Neuro-oncology. 2018;21(2):167-78.

39. Bell EH, Zhang P, Fisher BJ, Macdonald DR, McElroy JP, Lesser GJ, et al. Association of MGMT promoter methylation status with survival outcomes in patients with high-risk glioma treated with radiotherapy and temozolomide: an analysis from the NRG oncology/RTOG 0424 trial. JAMA Oncol. 2018:4(10):1405-9.

40. Alentorn A, Duran-Pena A, Pingle SC, Piccioni DE, Idbaih A, Kesari S. Molecular profiling of gliomas: potential therapeutic implications. Expert Rev Anticancer Ther. 2015;15(8):955-62

41. Idbaih A. OMICS and biomarkers of glial tumors. Rev Neurol. 2011;167(10): 691-8.

42. Xiong L, Wang F, Xie XQ. Advanced treatment in high-grade gliomas. J BUON. 2019:24(2):424-30.

43. Vuong $\mathrm{H}$, Duong $\mathrm{U}$, Altibi A, Ngo H, Pham T, Tran $\mathrm{H}$, et al. A meta-analysis of prognostic roles of molecular markers in papillary thyroid carcinoma. Endocr Connect. 2017;6:R8-R17 doi: 10.1530. In.: EC-17-0010.[PMC free article][PubMed] [Cross Ref].

44. Vuong HG, Altibi AM, Duong UN, Hassell L. Prognostic implication of BRAF and TERT promoter mutation combination in papillary thyroid carcinoma-a meta-analysis. Clin Endocrinol (Oxf). 2017;87(5):411-7.

45. Fernandes SG, Dsouza R, Pandya G, Kirtonia A, Tergaonkar V, Lee SY, et al. Role of telomeres and Telomeric proteins in human malignancies and their therapeutic potential. Cancers. 2020;12(7):1901.

46. Akincilar SC, Unal B, Tergaonkar V. Reactivation of telomerase in cancer. Cell Mol Life Sci. 2016;73(8):1659-70.

47. Kim HS, Kwon MJ, Song JH, Kim ES, Kim HY, Min K-W. Clinical implications of TERT promoter mutation on IDH mutation and MGMT promoter methylation in diffuse gliomas. Pathology-Res Pract. 2018;214(6):881-8.

48. Yu S, Xu T, Dai J, Ma M, Tang H, Chi Z, et al. TERT copy gain predicts the outcome of high-dose interferon $a-2 b$ therapy in acral melanoma. Onco Targets Ther. 2018;11:4097.

49. Bu R, Siraj AK, Divya SP, Kong Y, Parvathareddy SK, Al-Rasheed M, et al. Telomerase reverse transcriptase mutations are independent predictor of disease-free survival in $\mathrm{M}$ iddle $\mathrm{E}$ astern papillary thyroid cancer. Int J Cancer. 2018;142(10):2028-39.

50. Hurst CD, Platt FM, Knowles MA. Comprehensive mutation analysis of the TERT promoter in bladder cancer and detection of mutations in voided urine. Eur Urol. 2014;65(2):367-9.

51. Perry JR, Laperriere N, O'Callaghan CJ, Brandes AA, Menten J, Phillips C, et al Short-course radiation plus temozolomide in elderly patients with glioblastoma. N Engl J Med. 2017;376(11):1027-37. 
52. Álvarez de Eulate-Beramendi S, Álvarez-Vega MA, Balbin M, Sanchez-Pitiot A, Vallina-Alvarez A, Martino-González J. Prognostic factors and survival study in high-grade glioma in the elderly. Br J Neurosurg. 2016;30(3):330-6.

53. Uzuka T, Asano K, Sasajima T, Sakurada K, Kumabe T, Beppu T, et al. Treatment outcomes in glioblastoma patients aged 76 years or older: a multicenter retrospective cohort study. J Neurooncol. 2014;116(2):299-306.

54. Babu R, Komisarow JM, Agarwal VJ, Rahimpour S, lyer A, Britt D, et al. Glioblastoma in the elderly: the effect of aggressive and modern therapies on survival. J Neurosurg. 2016;124(4):998-1007.

55. Wager M, Menei $P$, Guilhot J, Levillain P, Michalak S, Bataille B, et al. Prognostic molecular markers with no impact on decision-making: the paradox of gliomas based on a prospective study. Br J Cancer. 2008;98(11):1830

56. Weller M, Stupp R, Reifenberger G, Brandes AA, Van Den Bent MJ, Wick W, et al. MGMT promoter methylation in malignant gliomas: ready for personalized medicine? Nat Rev Neurol. 2010;6(1):39.

57. Gilbert MR, Wang M, Aldape KD, Stupp R, Hegi ME, Jaeckle KA, et al. Dosedense temozolomide for newly diagnosed glioblastoma: a randomized phase III clinical trial. J Clin Oncol. 2013;31(32):4085.

58. Stupp R, Hegi ME, Mason WP, van den Bent MJ, Taphoorn MJ, Janzer RC, et al. Effects of radiotherapy with concomitant and adjuvant temozolomide versus radiotherapy alone on survival in glioblastoma in a randomised phase III study: 5-year analysis of the EORTC-NCIC trial. Lancet Oncol. 2009; 10(5):459-66.

59. Karachi A, Dastmalchi F, Mitchell DA, Rahman M. Temozolomide for immunomodulation in the treatment of glioblastoma. Neuro-oncology. 2018;20(12):1566-72.

60. Hegi ME, Stupp R. Withholding temozolomide in glioblastoma patients with unmethylated MGMT promoter—still a dilemma? Neuro Oncol. 2015;17(11):1425-7.

\section{Publisher's Note}

Springer Nature remains neutral with regard to jurisdictional claims in published maps and institutional affiliations.

Ready to submit your research? Choose BMC and benefit from:

- fast, convenient online submission

- thorough peer review by experienced researchers in your field

- rapid publication on acceptance

- support for research data, including large and complex data types

- gold Open Access which fosters wider collaboration and increased citations

- maximum visibility for your research: over $100 \mathrm{M}$ website views per year

At $\mathrm{BMC}$, research is always in progress.

Learn more biomedcentral.com/submissions 